\title{
TROCAS GASOSAS E TEOR DE CLOROFILA EM FOLHAS SOMBREADAS DE PLANTAS JOVENS DE SERINGUEIRA
}

Elenice de Cássia Conforto ${ }^{1}$, Regiane Peres Andreoli ${ }^{2}$, Juliane Ribeiro Cavalcante ${ }^{3}$

${ }^{1}$ Professora Assistente-Doutora. ${ }^{1}$ Universidade Estadual Paulista, Instituto de Biociências, Letras e Ciências Exatas. Rua Cristóvão Colombo, 2265, Jardim Nazareth. São José do Rio Preto, SP. CEP 15054-000. elenice@ibilce.unesp.br

${ }^{2}$ Bióloga.UNESP-IBILCE-SãoJosé do Rio Preto. regianep@ibilce.unesp.br

${ }^{3}$ Mestre. UNESP-IBILCE-SãoJosé do Rio Preto. jurc_biologa@yahoo.com.br

\section{RESUMO}

As seringueiras têm demonstrado notável capacidade para seqüestrar o carbono, e as folhas sombreadas respondem pela maior parte deste trabalho. Foi comparado o desempenho destas folhas, para plantas com 4 anos de idade, das cultivares RRIM 600 e Fx 3864, durante o período seco de 2004/05. A eficiência da carboxilação manteve o mesmo nível nos dois períodos, enquanto que a eficiência do uso da água aumentou durante o período mais seco (2004). Neste, as menores taxas de transpiração e do grau de condutância estomática indicaram que houve um comportamento preventivo contra o estresse hídrico. Nos dois períodos, os teores de clorofila total e da taxa fotossintética foram maiores que os relatados na literatura, e no período menos seco (2005), RRIM 600 apresentou melhor desempenho que Fx 3864 quanto a estes dois caracteres.

Palavras-chave: RRIM 600, Fx 3864, eficiência da carboxilação, eficiência do uso de água

\section{GAS EXCHANGE AND CHLOROPHYLL CONTENT IN SHADOWED LEAVES OF TWO YOUNG RUBBER TREE CULTIVARS}

\begin{abstract}
Rubber trees have shown exceptional capacity for carbon sequestration, and the shadowed leaves realise the most part of it. This study aimed to compare the performance of the leaves of two cultivars (RRIM 600 and Fx 3864), both at the age of four years, during the dry seasons of 2004/05. The carboxilation efficiency keept the same level for both periods, while the water use efficiency increased during the driest season (2004). In this period, the lowest transpiration rate and stomatal conductance indicated a preventive response to water stress. The chlorophyll content and photosynthetic rate were higher than those reported by other studies, in both periods; however, during the least dry period, RRIM 600 showed a better performance than Fx 3864 concerning to these characteres.
\end{abstract}

Key words: RRIM 600, Fx 3864, carboxilation efficience, water use efficience. 


\section{INTRODUÇÃO}

Nos últimos anos, atenção tem sido dada à heveicultura quanto ao aspecto ambiental. Um hectare de seringueira pode gerar créditos sobre mais de 1.000 toneladas de dióxido de carbono equivalente $\left(\mathrm{CO}_{2} \mathrm{e}\right)$, enquanto que o eucalipto pode fixar cerca de 317 toneladas de $\mathrm{CO}_{2} \mathrm{e}$ na mesma área (Borracha via e-mail, 2003), demonstrando uma excepcional habilidade para seqüestrar o carbono atmosférico.

A fotossíntese sob condições de baixa irradiância é fundamental para o balanço de carbono, visto que as folhas das camadas superiores de uma plantação madura, com índice de área foliar acima de seis, interceptam até $75 \%$ da radiação fotossinteticamente ativa incidente, enquanto que uma significativa porção do total da área foliar, presente nas camadas inferiores da copa, está exposta a uma radiação subsaturante de cerca de 100-200 $\mu \mathrm{mol} \mathrm{m} \mathrm{m}^{-2} \mathrm{~s}^{-1}$ (Nataraja \& Jacob, 1999). Estudos de Senevirathna et al. (2003) revelaram que, nas plantas sombreadas, a assimilação de $\mathrm{CO}_{2}$ tendeu a saturar em baixa densidade de fluxo de fótons fotossinteticamente ativos, e com valores mais baixos de fotossíntese máxima que nas plantas de sol.

Para seringueiras crescidas sob condições de campo, a chuva é a principal fonte de umidade. Associando o sombreamento à variação sazonal da disponibilidade hídrica do solo, é formando um painel que torna os estudos mais complexos, mas fundamentais para a compreensão dos processos adaptativos desta espécie agrícola.

Segundo Tardieu (2005), as estratégias para as plantas cresceram em climas secos depende essencialmente dos mesmos tipos de escolha, que podem ser através do escape, evitamento ou resistência. Para seringueiras, os principais aspectos avaliados para analisar a capacidade da planta em tolerar um déficit hídrico elevado referem-se à sensibilidade estomática à troca gasosa e à capacidade de manter alto teor hídrico na folha (Brunini \& Cardoso, 1998).

Devido à influência das folhas autosombreadas no balanço de carbono da seringueira, este estudo foi conduzido de modo comparativo para duas cultivares jovens, durante períodos secos dos anos 2004/05.

\section{MATERIAL E MÉTODOS}

Foram estudadas as cultivares RRIM 600 e Fx 3864 (enxertadas sobre $\mathrm{Tj}$ 16), mantidas na Área Experimental do Departamento de Zoologia e Botânica da UNESP-IBILCE-São José do Rio Preto, SP, Brasil (latitude Sul de $20^{\circ} 49^{\prime} 11^{\prime \prime}$ e longitude Oeste de 49 $\left.22^{\prime} 46^{\prime \prime}\right)$. O solo do local é do tipo argissolo vermelho-amarelo, com textura arenosa média, em fase de relevo suave ondulado, variação Lins Marília (Prado, 2000). O delineamento experimental foi casualizado, tendo sido as plantas dispostas em parcelas lineares, espaçadas em $1,80 \mathrm{~m}$ entre plantas e 2,0 $\mathrm{m}$ entre as linhas.

As observações foram realizadas durante os meses de setembro de 2004 e abril de 2005, quando as plantas contavam com, respectivamente, 45 e 52 meses de idade. Os parâmetros climáticos foram obtidos junto ao Centro Integrado de Informações Agrometeorológicas (CIIAGRO, 2005).

As trocas gasosas de água e dióxido de carbono foram mensuradas com uso do monitorador portátil de trocas gasosas por infra-vermelho (ADC, UK, modelo LCA-4). As medidas foram realizadas no período entre 8 e 10 horas (mais propício para as trocas gasosas, segundo Eamus et al., 1999), utilizando-se folhas intactas de ramos destacados, provenientes do extrato inferior da copa. Foram utilizadas quatro plantas (repetições), com três determinações por. planta. A eficiência da carboxilação foi calculada pela relação $\mathrm{A} / \mathrm{CiCO}_{2}$ (Nataraja \& 
Jacob 1999), e a eficiência do uso da água, pela relação A/E.10 $0^{-3}$ (Kramer \& Boyer, 1995).

Em plantas com idade de 52 meses, foi coletado material foliar para análise do teor total de clorofila (Senevirathna et al. 2003), com 10 repetições para cada clone. Por tratar-se de coleta única, foram analisadas também as folhas expostas ao sol.

Os valores das trocas gasosas foram comparados pelo teste $\mathrm{F}$ com uso do "software" Microcal Origin 4.0 (1995); os teores de clorofila foram analisados pelo teste $\mathrm{F}$ e as médias foram comparadas pelo teste de Tukey com uso do "software" SAS 1990, segundo Zar (1999).

\section{RESULTADOS E DISCUSSÃO}

Parâmetros Ambientais. $\mathrm{O}$ primeiro experimento foi realizado em outubro/2004, após um período de 72 dias sem chuvas, onde foi acumulada uma evapotranspiração real (ETR) de $105 \mathrm{~mm}$ e déficit hídrico (DH) de $122 \mathrm{~mm}$; na semana dos experimentos, a ETR foi de $5 \mathrm{~mm}$ e o DH, de $25 \mathrm{~mm}$.

$O$ segundo experimento foi realizado em abri1/2005, após um período de 20 dias sem chuvas, onde foi acumulada uma ETR de $58 \mathrm{~mm}$ e DH de $18 \mathrm{~mm}$. Durante a semana de realização dos experimentos, aconteceu uma pequena precipitação (2 $\mathrm{mm}$ ); a ETR foi de $16 \mathrm{~mm}$, e o DH de 9 $\mathrm{mm}$, evidenciando que o primeiro experimento foi realizado sob condições de mais intenso déficit hídrico.

Trocas Gasosas. Os valores verificados nos dias de experimento são mostrados na Tabela 1.

Tabela 1.Valores médios da taxa fotossintética (A), taxa de transpiração (E), condutância estomática (gs), concentração de gás carbônico na câmara subestomática $\left(\mathrm{CiCO}_{2}\right)$, eficiência da carboxilação $\left(\mathrm{A} / \mathrm{CiCO}_{2}\right)$ e eficiência do uso da água $(\mathrm{A} / \mathrm{E})$ para os cultivares de seringueira RRIM 600 e FX 3864.

\begin{tabular}{cccccc}
\hline $\begin{array}{c}\text { Cultivar/ } \\
\text { Ano }\end{array}$ & $\begin{array}{c}\mathrm{A} \\
\mu \mathrm{molm}^{-2} \mathrm{~s}^{-1}\end{array}$ & $\begin{array}{c}\mathrm{E} \\
\mathrm{mmolm}^{-2} \mathrm{~s}^{-1}\end{array}$ & $\begin{array}{c}\mathrm{gs} \\
\mathrm{molm}^{-2} \mathrm{~s}^{-1}\end{array}$ & $\mathrm{CiCO}_{2}$ & $\begin{array}{c}\text { Efic.do uso } \\
\text { de água }\end{array}$ \\
\hline 2004 & & & & & \\
RRIM 600 & $3,95(1,38)$ & $1,60(0,67)$ & $0,06(0,039)$ & $0,025(0,0002)$ & $3,11(0,25)$ \\
Fx 3864 & $3,44(1,16)$ & $1,35(0,58)$ & $0,04(0,016)$ & $0,023(0,0014)$ & $3,11(0,62)$ \\
F & $2,56 \mathrm{~ns}$ & $2,53 \mathrm{~ns}$ & $10,01^{*}$ & $0,40 \mathrm{~ns}$ & $0,004 \mathrm{~ns}$ \\
2005 & & & & & \\
RRIM 600 & $4,95(1,86)$ & $2,88(0,88)$ & $0,094(0,0457)$ & $0,024(0,0009)$ & $1,37(0,68)$ \\
Fx 3864 & $4,21(1,84)$ & $2,73(0,73)$ & $0,074(0,032)$ & $0,024(0,0012)$ & $1,26(0,43)$ \\
F & $11,66^{*}$ & $0,35 \mathrm{~ns}$ & $2,85 \mathrm{~ns}$ & $0,117 \mathrm{~ns}$ & $30,25^{*}$ \\
\hline
\end{tabular}

* médias estatisticamente diferentes com $\mathrm{P}=0,05$.

Desvio-padrão entre parêntesis.

É amplamente relatado na literatura que plantas crescidas sob o sol apresentam maior produtividade fotossintética porque recebem radiação saturante durante todo o dia. Estudos com folhas sombreadas realizados por Nataraja \& Jacob (1999) para
12 cultivares crescidos sob baixa irradiação, indicaram valores entre 2,4 a $3,8 \mu \mathrm{mol} \mathrm{m}$ $\mathrm{s}^{-1}$, menores que as do presente estudo.

No período mais seco, a taxa fotossintética decresceu na ordem de $20,2 \%$ para RRIM 600 e de $18,3 \%$ para Fx 3864 . 
Esta redução é menor que a verificada para folhas de sol por Cavalcante (2003), que mensurou uma queda de $32 \%$ para RRIM 600 e de $22 \%$ para Fx 3864, comparando-se as taxas entre os períodos úmido e seco.

A EUA variou entre os limites típicos de uma planta C 3 (entre 1 e 3, segundo Larcher, 2000), sendo maior no período mais seco, devido à redução no grau de abertura estomática e na taxa de transpiração, indicando um comportamento preventivo à desidratação do tecido, que evita uma dessecação maior no período seco.

A eficiência da carboxilação foi mantida no mesmo nível, para as duas cultivares, nos dois períodos. Segundo Farquhar apud Nataraja \& Jacob (1999), $\mathrm{A} / \mathrm{CiCO}_{2}$ é a medida da atividade da enzima carboxilase nas folhas. Sob condições normais, a maior parte do controle do mesofilo sobre a fotossíntese é operada no sítio da Rubisco, pois sua taxa limita a bioquímica fotossintética; assim, a relação $\mathrm{A} / \mathrm{CiCO}_{2}$ é um índice da capacidade fotossintética do mesofilo. Em seringueiras, esta relação é fracamente relacionada com a condutância estomática, indicando que, para Hevea, os fatores do mesofilo desempenham um papel muito mais importante que o da condutância estomática sobre a regulação da fotossíntese. Assim, a eficiência manteve-se relativamente constante, apesar do menor suprimento hídrico no ano de 2004.

Conteúdo de Clorofila. Os valores médios apresentaram diferenças significativas entre as cultivares $(\mathrm{F}=77,93, \mathrm{P}=0,05)$, e mostrou influência do nível de luminosidade sobre Fx 3864. Nestas, os valores foram de 1,210 $\mu \mathrm{g} / \mathrm{cm}^{2}$ e $1,288 \mu \mathrm{g} / \mathrm{cm}^{2}$ nas folhas iluminadas e sombreadas, respectivamente, enquanto que para a cultivar RRIM 600 os valores foram de $1,427 \mu \mathrm{g} / \mathrm{cm}^{2}$ e 1,470 $\mu \mathrm{g} / \mathrm{cm}^{2}$, respectivamente, não diferindo entre si. Embora todos os teores tenham sido superiores aos verificados por Senevirathna et al. (2003) para plantas sob nível de sombreamento artificial de $33 \%$ (nível próximo ao verificado para as plantas do presente estudo), estes autores verificaram alterações no nível de clorofila apenas quando o sombreamento atingiu $77 \%$, o que indica que a cultivar Fx 3864 foi mais sensível ao sombreamento.

\section{CONCLUSÃO}

Comparado aos valores da literatura, as folhas sombreadas das duas cultivares mantiveram um bom desempenho, apesar do período seco, com indicativos de melhor resposta para RRIM 600 .

\section{AGRADECIMENTOS}

Á Bióloga Maria Helena Carabolante, pelo auxílio nas análises do teor de clorofila, e à FAPESP, pelo financiamento dos equipamentos utilizados nesta pesquisa.

\section{REFERÊNCIAS BIBLIOGRÁFICAS}

BORRACHA VIA E-MAIL. 2003. Ano IV, $\mathrm{n}$. 149. $<$ http://www.borrachanatural.agr.br>. Acesso em: 14.jan.2005.

BRUNINI, O.,CARDOSO, M. 1998. Efeito do déficit hídrico do solo sobre o comportamento estomático e potencial da água em mudas de seringueira. Pesquisa Agropecuária Brasileira, 33, (7): 1053-1060..

CAVALCANTE, J. R. 2003. Fotossíntese, relações hídricas, estado nutricional e avaliação de caracteres secundários da produção em dois cultivares jovens de seringueira em São José do Rio Preto, SP. 84f. Dissertação (Mestrado em Ecologia e 
Recursos Naturais)- Universidade Federal de São Carlos, São Paulo.

CIIAGRO. 2005. Centro Integrado de Informações Agrometeorológicas Disponível em $<$ http://ciiagro.iac.sp.gov/br/sciiagroon line>. Acesso em: 20/04/2005.

EAMUS, D., MYERS, B., DUFF, G., WILLIAMS, 1999.

Ecophysiological traits of deciduous and evergreen woody species in the seasonally dry tropics. Tree, 14 (1): 11-16.

KRAMER, P. J., BOYER, J. S. 1995. Water relations of plants and soils. San Diego, Academic Press. 495p.

LARCHER, W. 2000. Ecofisiologia Vegetal . Trad. Carlos Henrique B. A . Prado. São Carlos: RiMa. 531p

MICROCAL ORIGIN. 1995. Origin Version 4.0. Microcal Software, Inc: Northampton, MA. Número de Série 6025888 .
NATARAJA , K. N., JACOB, J. 1999. Clonal differences in photosynthesis in Hevea brasiliensis Müell. Arg. Photosynthetica, 36,(1-2): 89-98.

PRADO, H. 2000. Solos do Brasil: gênese, morfologia, classificação e levantamento. Piracicaba: Fundação Biblioteca Nacional. 181p.

SAS Institute Inc. 1990. SAS/STAT: Guide version $6.3^{\text {a }}$. ed. Cary, NC: SAS Institute. $385 \mathrm{p}$.

SENEVIRATHNA, A. M. W.K., STIRLING, $\quad$ C.X.M., RODRIGO,V.H.L. 2003. Growth, photosynthetic performance and shade adaptation of rubber (Hevea brasiliensis) grown in natural shade. Tree Physiology, 23: 705-712.

TARDIEU, F. 2005. Plant tolerance to water deficit: physical limits and possibilities for progress. Comptes Rendus Geoscience, 337: 57-67.

ZAR, J. H. 1999. Bios tatistical Analysis. New Jersey: Prentice Hall. 663p. 